\title{
A VIOLÊNCIA DE GÊNERO CONTRA A MULHER NA PERCEPÇÃO DE AGENTES COMUNITÁRIOS DE SAÚDE
}

GENDER VIOLENCE AGAINST WOMAN IN THE PERCEPTION OF COMMUNITY HEALTH AGENTS

\author{
Ludmila de Moura', Carlos Roberto Castro-Silva²
}

RECEBIDO EM: 28/08/2017 / APROVADO EM: 15/09/2017

DOI: $10.5902 / 2317175827606$

\section{RESUMO}

A violência é um fenômeno que atinge a ambos os sexos, porém tem incidência especial sobre mulheres, negras e pobres. O Brasil encontra-se no 50 lugar em relação a 83 países. Entre 2003 e 2013 houve um aumento de $21 \%$ no número de mulheres assassinadas, representando 13 feminicídios por dia. Por conta disso, esta pesquisa teve por objetivo compreender as percepções e os sentidos atribuídos ao fenômeno da violência de gênero no âmbito doméstico, contra a mulher, a partir das práticas dos/as agentes comunitários de saúde (ACS) em ações em território de alta vulnerabilidade social. Os achados foram analisados baseados nos pressupostos da psicologia sócio histórica e da epistemologia qualitativa de González Rey. Através da observação participante, a pesquisadora acompanhou os/as agentes em visitas domiciliares, que resultou na elaboração de 20 diários de campo, além de entrevistas abertas com duas ACS. Os resultados obtidos foram analisados pela categoria empírica "Violência de Gênero", segundo duas óticas: "ser mulher" e "a violência por parceiro íntimo". A "naturalização" da violência na comunidade também foi problematizada, juntamente com o patriarcado enquanto discurso normativo articulado com o capitalismo, na busca de explicação da opressão das mulheres pelos homens.

Palavras-chave: Agente comunitário de saúde; Gênero; Violência de gênero; TrabaIho em saúde; Vulnerabilidade social.

1 Doutoranda na Pós-graduação Interdisciplinar em Ciências da Saúde, na UNIFESP-Baixada Santista, desde julho de 2014, pesquisando sobre a atuação de Agentes Comunitários de Saúde em relação à violência de gênero. 2 Possui pós-doutoramento em Ciências Sociais pela University of Western Ontario, Canadá (2006). Doutorado em Psicologia Social pela Universidade de São Paulo (2004). Mestrado em Psicologia (Psicologia Social) pela Pontifícia Universidade Católica de São Paulo (1998) e Especialização em Saúde Coletiva pelo Departamento de Medicina Social da Faculdade de Medicina da USP. Atualmente é professor adjunto da Universidade Federal de São Paulo - Baixada Santista (UNIFESP). 
A VIOLÊNCIA DE GÊNERO CONTRA A MULHER NA

PERCEPÇÃO DE AGENTES COMUNITÁRIOS DE SAÚDE

\begin{abstract}
Violence is a phenomenon that affects both sexes, but has a special incidence on women, black and poor. Brazil is in 5th place in relation to 83 countries. Between 2003 and 2013 there was a $21 \%$ increase in the number of women murdered, representing 13 femicides per day. The objective of this research was to understand the perceptions and meanings attributed to the phenomenon of domestic violence against women, based on the practices of the com- munity health agents (ACS) in actions in a territory of high social vulnerability. The findings were analyzed based on the assumptions of socio-historical psychology and the qualitative epistemology of González Rey. Through the participant observation, the researcher followed them in home visits, which resulted in the elaboration of 20 field diaries, as well as open interviews with two ACS. The results obtained were analyzed by the empirical category "Gender

Violence", according to two perspectives: "being a woman" and "violence by an intimate partner". The "naturalization" of violence in the community was also problematized, along with patriarchy as normative discourse articulated with capitalism, in search of an explanation of the oppression of women by men.
\end{abstract}

Keywords: Community health agente; Gender; Gender violence; Healthcare work; Social vulnerability.

\title{
1 Introdução
}

Desde a modernidade, a violência é vista como um problema social, mas só foi reconhecida como um problema de saúde pública pela OMS (Organização Mundial de Saúde) em 1996 e publicada no Relatório Mundial de Saúde no ano de 2002 (ARAÚJO, 2008; LIMA et al, 2008; MINAYO; SOUZA, 1998; WHO, 2002), além de ser uma clara violação dos direitos humanos (MINAYO, 2006). No Brasil, esse reconhecimento é recente, em torno de 30 anos (PASINATO, 2015), sendo que, em 2001, essa abordagem foi institucionalizada através da Política Nacional de Redução da Morbimortalidade por Acidentes e Violências (BRASIL, 2001).

$A$ violência é um fenômeno que atinge a ambos os sexos, porém tem incidência especial sobre o sexo feminino. A violência de gênero contra a mulher é muito antiga e acompanha grande parte da história da humanidade. Nesse sentido, $35 \%$ de todas as queixas nos serviços de saúde pública no Brasil, refere-se às violências do homem contra a mulher (MINAYO, 2006; WAISELFISZ, 2015). Em relação aos homicídios de mulheres, os dados mais atuais colocam o Brasil no 5 o lugar em relação a 83 países. Entre 2003 e 2013 houve um aumento de $21 \%$ no número de mulheres assassinadas, representando 13 feminicídios por dia. Em se tratando de mulheres negras, os dados são mais alarmantes, pois os homicídios aumentaram 54,2\% na mesma década (WAISELFISZ, 2015). Feminicídio é conceituado como o assassinato de mulheres baseado nas "relações desiguais de poder entre os gêneros" (MENEGHEL, 2015, p. 148).

A violência contra a mulher é um fenômeno que deve ser visto relacionado às condições econômicas, sociais e culturais de uma sociedade, 
incluindo as características patriarcais de nossa cultura (AGUIAR, 2015). Para o estudo da violência, é necessário uma visão dialética da relação entre indivíduo e sociedade. Não se pode negar o mundo subjetivo que se relaciona com a vida social e privada: "Existe uma complementaridade dinâmica entre o biológico, o psicológico, o social e o ecológico" (MINAYO; SOUZA, 1998, p.525). E é no indivíduo que a violência ocorre, seja como vítima ou como agressor:

Como unidade dialética, o ser humano sintetiza em seus componentes psíquicos e emocionais as representações que elabora do mundo, das relações nele estabelecidas e de si mesmo, enquanto ser corpóreo e sujeito social. Só considerando a subjetividade podemos compreender por que em uma mesma família um membro opta por comportamentos violentos e outro não [...] busca também compreender o comportamento de pessoas que preferem ser reconhecidas por atos violentos a não terem reconhecimento algum (MINAYO; SOUZA, 1998, p. 526).

Essas autoras consideram a contribuição da Psicologia fundamental para compreender que entre o biológico, o cultural e o social, existem nos indivíduos os desejos, as emoções e as pulsões.

Profissionalmente, predominantemente cercada por mulheres (e como uma) - profissionais e usuárias da área da saúde, deparava-me com questionamentos sobre a condição feminina, as diferenças e desigualdades, conforme o pertencimento a determinada classe social, etnia e gênero. Trouxe comigo o incômodo com as desigualdades e violências de gênero e o interesse pela área da saúde para o curso de doutorado Interdisciplinar em Ciências da Saúde, realizado na UNIFESP Baixada Santista, desde o ano de 2014 através da orientação do segundo autor, que já desenvolvia outras pesquisas com agentes comunitários de saúde (ACS) (CASTRO-SILVA, 2011), na Vila dos Pescadores (VP), no município de Cubatão, no litoral sul do estado de São Paulo.

A partir daquelas pesquisas, pode-se perceber que o tema da violência estava presente na fala de alguns profissionais de saúde entrevistados, o que levou ao interesse de pesquisar especificamente sobre a violência de gênero nesta comunidade, através das percepções dos/as ACS, visto que suas práticas tem forte ligação com a realidade da comunidade, na qual se deparam diariamente com as demandas cotidianas dos munícipes, o que possibilita o fortalecimento do vínculo entre profissionais e sujeitos. Estudos também apontam a importância do papel dos/as ACS no rastreamento para a detecção da violência contra a mulher (LIRA et al, 2012), visto que suas concepções valorativas vão ter impacto significativo em suas formas de atuação.

Sendo assim, esta pesquisa teve por objetivo compreender as percepções e os sentidos atribuídos ao fenômeno da violência de gênero (VG) no âmbito doméstico, contra a mulher, a partir das práticas dos/as ACS em ações da Estratégia de Saúde da Família (ESF) em território de alta vulnerabilidade social.

Os achados serão analisados baseados nos pressupostos da psicologia sócio histórica (BOCK, 2011) e da epistemologia qualitativa de González Rey (2011). 


\section{Referencial teórico}

Para abordar a violência de gênero contra a mulher na área da saúde, faz-se necessário inicialmente contextualizar a questão da violência e do marcador social gênero.

\subsection{A violência}

Considerada um fenômeno sócio histórico, a violência está presente em todas as sociedades, de forma lícita ou ilícita, aceita ou desaprovada conforme as normas sociais mantidas pela cultura e pelos dispositivos legais de determinada comunidade. Manifesta-se de variadas formas, como conflitos de autoridade, lutas de poder, vontade de domínio, de posse e de aniquilamento do outro e de seus bens, através de guerras, discriminações, atos terroristas etc, apresentando mudanças na sua forma de expressão a partir do avanço tecnológico (MINAYO, 2006; WHO, 2002).

Engendrado na cultura brasileira está o mito de que somos um povo muito pacífico (IANNI, 2002), porém dados do Sistema de Informações sobre Mortalidade (SIM), do Ministério da Saúde, divulgados no Atlas da Violência 2016, apontam que, em 2014, houve 59.627 homicídios no Brasil, correspondendo a uma taxa de 29,1 homicídios por 100 mil habitantes. Isso nos coloca entre os 12 países com maiores taxas de homicídios por $100 \mathrm{mil}$ habitantes, em um ranking de 154 países (IPEA, 2016). Esses números colocam o Brasil em primeiro lugar com o maior número absoluto de homicídios e representam mais de $10 \%$ dos homicídios no mundo.

Embora a violência perpasse todas as camadas sociais, seus efeitos são mais graves e duradouros sobre as populações historicamente excluídas e mais vulneráveis, como os negros, mulheres, indígenas e membros dos grupos LGBT (AGOSTINI, 2015). Em relação às mulheres, essa violência se sustenta pela cultura patriarcal, que estabelece relações hierárquicas entre os gêneros, em que e os homens assumem papéis sociais dominantes e mais valorizados, com um expressivo exercício de poder sobre as mulheres (AGUIAR, 2015; MINAYO, 2006; SAFFIOTI, 2004).

\subsection{Gênero}

Gênero é compreendido enquanto elemento integrante das relações sociais, tendo como base as diferenças percebidas entre os sexos, dando significado às relações de poder. Ou seja, a diferença entre os sexos (biológico) é transformada em desigualdade social, do poder do homem sobre as mulheres (SCOTT, 1988). Minayo (2006, p. 93) acrescenta que "as características de gênero se fundam na hierarquia e na desigualdade de lugares sexuados".

Assim como gênero, sexo e sexualidade são construtos aprendidos, historicamente construídos segundo a cultura em que nos desenvolvemos, 
influenciados por diversos marcadores sociais como raça/etnia, idade, classe, orientação sexual etc (ARAÚJO, 2008; ROMANI, 2015; SAFFIOTI, 2001; 2004).

Estudos realizados, principalmente a partir da década de 70 , vieram confirmar e ampliar essas ideias sobre a "diversidade de sentidos assumidos pelas categorias 'mulher' e 'homem', em diferentes contextos culturais, [pois] demonstra claramente que as diferenças biológicas entre os sexos não podem constituir uma base universal para definições sociais" (MOORE, 1997, p. 2). Para a historiadora norte americana Joan Scott:

[...] gênero se torna, aliás, uma maneira de indicar as 'construções sociais' - a criação inteiramente social das ideias sobre os papéis próprios aos homens e às mulheres. É uma maneira de se referir às origens exclusivamente sociais das identidades subjetivas dos homens e das mulheres (SCOTT, 1988, p. 7).

Gênero também é utilizado como uma ferramenta de análise das relações entre homens e mulheres, entre mulheres e mulheres, entre homens e homens, em seus múltiplos processos evolutivos e educativos (social, cultural e linguístico), que levaram o ser humano a reconhecer-se como homem/mulher, pai/mãe, dependendo de sua condição social. A classificação e hierarquização social salientaram as diferenças de força entre ambos, tornando inscrito no corpo físico a identidade de gênero. E por múltiplos motivos históricos, o caráter relacional embrenha-se, muitas vezes, por disputas e divergências (MATOS, 2015; PISCITELLI, 2002).

A filósofa e feminista norte americana Judith Butler (2016) vai além, questionando a dicotomia sexo $X$ gênero, pois nem sexo, nem a sexualidade seriam verdades essenciais, universais, mas construções discursivas de acordo com cada sociedade, em cada momento histórico: "O gênero não deve ser meramente concebido como a inscrição cultural de significado num sexo previamente dado [...], tem de designar também o aparato mesmo de produção mediante o qual os próprios sexos são estabelecidos (p. 25) ".

Estamos em uma sociedade, segundo Butler (2016), em que existe uma "ordem compulsória" da heterossexualidade sobre o sexo, o gênero e o desejo/ prática, criando uma ideia de "estabilidade" assegurada pela oposição binária de masculino/feminino, macho/fêmea, homem/mulher. Assim, essas normas culturalmente repetidas por atos, gestos e signos, levam à constituição de corpos aparentemente masculinos e femininos (PISCITELLI, 2002; ROMANI, 2015).

Assim explicado, para Butler (2002, p. 34), o gênero é performático, "de modo que a performatividade não é um 'ato' singular, porque sempre é a reiteração de uma norma ou um conjunto de normas e, na medida em que adquire a condição de ato no presente, oculta ou dissimula as convenções de que é uma repetição".

O processo de socialização de homens e mulheres foi construindo, ao longo da história, o poder masculino sobre as mulheres. Essa relação de poder é conceituada como patriarcado, abrangendo uma relação civil que dá direitos 
sexuais ao homem sobre as mulheres, quase que sem restrições, que permeia muitos países, com base material, solidifica-se e tem caráter ideológico (AGUIAR, 2015; SAFFIOTI, 2004).

Não há um poder patriarcal com sua forma de opressão masculina único, nem uma maneira apenas de resistência por parte das mulheres, por isso, patriarcado também não pode ser visto como uma categoria universal, mas se expressa de formas diferentes em variados contextos, a despeito do imaginário social normativo. Apesar da secular opressão patriarcal que tem sido imposta às mulheres, além da resistência de muitas mulheres, há estudos que mostram famílias que se organizam de uma forma mais colaborativa (AGUIAR, 2015; ARAÚJO, 2008).

Joan Scott e Judith Butler analisam gênero além da ótica do "patriarcado". Consideram que não há uma dominação absoluta do homem sobre a mulher, pois a questão do gênero é relacional, questionando as categorias "universais" homem e mulher (BUTLER, 1990, 2016; PISCITELLI, 2002; SCOTT, 1988).

\subsection{Violência de gênero contra a mulher}

A violência de gênero ocorre no cotidiano das relações das mulheres com os homens, principalmente por companheiros ou ex-companheiros, no âmbito privado. Na literatura, não existe um consenso em relação aos termos utilizados para designar esse fenômeno complexo que é a violência contra a mulher: violência doméstica, violência intrafamiliar, violência de gênero, violência de parceiro íntimo, violência conjugal e mulher golpeada, são muitas vezes usados como sinônimos, apesar de suas especificidades enquanto categorias analíticas (ARAÚJO, 2008; SAFFIOTI, 2004). Mas a violência de gênero do homem contra a mulher é o tipo mais frequente devido às desigualdades historicamente construídas (ARAÚJO, 2008; LIMA et al, 2008; MINAYO, 2006), sendo também por isso que será abordada neste trabalho.

Embora desde a Carta das Nações Unidas de 1945 e da Declaração Universal dos Direitos Humanos em 1948 defenda-se a igualdade entre homens e mulheres e a eliminação de qualquer tipo de discriminação, esses direitos têm sido sistematicamente violados. Muitas conferências e convenções ocorreram buscando implementar e garantir a plena igualdade de gênero, tais como: a primeira Conferência Mundial da ONU, sobre a mulher, no México em 1975, juntamente com a comemoração do Ano Internacional da Mulher, seguidas pelas conferências em Copenhague - 1980, Nairobi em 1985 e em Beijing/China em 1995; em 1979 a Assembleia Geral da ONU adotou a Convenção sobre a Eliminação de Todas as Formas de Discriminação contra as Mulheres; em 1993 realizou-se a Conferência Internacional sobre Direitos Humanos, na Áustria; em 1994 ocorreu a Convenção do Cairo; também em 1994, em Belém do Pará ocorreu a Convenção Interamericana para Prevenir, Punir e Erradicar a Violência contra a Mulher; em 2000 foi estabelecido os Oito Objetivos de Desenvolvimento do Milênio, buscando solucionar problemas como a pobreza e a desigualdade de gênero (BANDEIRA; 
ALMEIDA, 2015; MARTINS; CERQUEIRA; MATOS, 2015). Inclusive a Convenção de Belém do Pará serviu de base para a fundamentação da Lei 11.340, conhecida como Lei Maria da Penha (BRASIL, 2006b), configurando "violência doméstica e familiar contra a mulher qualquer ação ou omissão baseada no gênero que Ihe cause morte, lesão, sofrimento físico, sexual ou psicológico e dano moral ou patrimonial" seja "no âmbito da unidade doméstica, [...], no âmbito da família [...] ou "em qualquer relação íntima de afeto".

Essas diferentes conferências e tratados, fruto de lutas feministas e de movimentos da sociedade civil organizada, tiraram as questões das desigualdades sofridas pelas mulheres do ambiente doméstico, trazendo à luz para questões internacionais e de políticas públicas. No Brasil, as políticas públicas de enfrentamento da violência contra a mulher resultam também de várias lutas feministas no combate à violência doméstica e familiar, como a participação nos conselhos de direitos das mulheres, sendo que no período entre 1960 e 1970 trouxeram a questão da violência contra a mulher para o espaço público, com o slogan "o pessoal é político" (MARTINS; CERQUEIRA; MATOS, 2015). Há três momentos marcantes nessa luta, segundo Santos (2008): a primeira delegacia da mulher, criada em 1985, em São Paulo; a criação dos Juizados Criminais Especiais (JECrims), depois de 1995; e a Lei no 11.340, Lei Maria da Penha, promulgada em 2006. Nota-se que basicamente é só depois de uma década de luta feminista que alguma mudança nas políticas públicas é implementada.

A violência de gênero contra a mulher é um fenômeno que atinge mulheres de diferentes classes sociais, faixa etária, nível educacional, etnias, religiões e culturas, sendo um fenômeno considerado universal, independente do nível de desenvolvimento econômico e social de uma população (LIRA et al, 2012; MINAYO, 2006). Mas essa "universalidade" se manifesta de formas diferentes conforme a classe social, a etnia e a religião a que a mulher vítima pertença, tendo consequências mais graves sobre grupos socialmente vulneráveis, principalmente sobre mulheres negras e pobres (AGOSTINI, 2015; WAISELFISZ, 2015).

Dados mais recentes sobre a Violência de Gênero no Brasil apontam que 13 mulheres são assassinadas por dia em nosso país, tomando por base o ano de 2014 do Atlas da Violência 2016, quando 4.757 mulheres foram vítimas de mortes por agressão (IPEA, 2016). Essas informações só fortalecem a necessidade de políticas públicas efetivas no combate à violência de gênero, pois segundo o IPEA, é um fenômeno diferente da violência contra os homens jovens (2016, p. 29): "[...] e exige, necessariamente, ações específicas que considerem os vínculos estabelecidos entre vítima e agressor, relações de dependência financeira e/ou emocional".

Uma resposta política foi a criação da Lei Maria da Penha, ao estabelecer medidas de prevenção, proteção, assistência e repressão à violência de gênero, mas também se faz necessário redes de atendimento e serviços disponíveis para proteção e manutenção da vida dessas mulheres (IPEA, 2016), pois grande parte dos serviços ainda se concentram nas capitais e na região Sudeste, principalmente no Estado de São Paulo (OBSERVE, 2010). 
As Delegacias Especializadas de Atendimento às Mulheres (DEAMs) concretizam a criminalização da violência contra mulheres, responsabilizando o Estado pela implantação de políticas públicas de enfrentamento a esse fenômeno.

Mesmo com os instrumentos de políticas públicas voltados ao enfrentamento da violência contra as mulheres, os serviços especializados de atendimento como as DEAMs implantadas, os aparatos legais como a Lei Maria da Penha e a Lei do Feminicídio de 2015, que torna o feminicídio crime hediondo, dados do IPEA (2016) mostram que a taxa de homicídios contra as mulheres tem aumentado, sem falar da violência que não é visível. Entretanto, não se pode atribuir esse fato apenas à efetividade ou não das ações de punição aos agressores, porém há um forte fator cultural que colabora para a perpetuação desse tipo de violência, como o patriarcado.

Refutando as críticas de que as leis de proteção à mulher não estão funcionando, Cerqueira e Coelho (2015) calculam que se não houvesse a Lei Maria da Penha e outras políticas de proteção à mulher, os homicídios dentro de casa teriam crescido pelo menos em $10 \%$.

Lembrando que a violência de gênero é uma afronta aos direitos humanos, devemos enfatizar a importância e a necessidade de que os serviços de proteção à mulher devem estar melhor estruturados no âmbito dos municípios e estados, para além dos grandes centros urbanos. A atuação das/os agentes comunitários de saúde inclusive se insere na lógica das redes de atendimento em nível local, que devem integrar os diferentes serviços públicos de atendimento em uma lógica intersetorial, não apenas junto a serviços especializados, como também junto aos serviços de assistência social, saúde, segurança pública, por exemplo, já existentes nos municípios (PASINATO, 2015).

\subsection{A Violência de gênero como uma questão de saúde}

A violência, enquanto processo social, não se restringe à área da saúde, mas é nesse setor que a maioria das vítimas são socorridas, além de estabelecer o importante papel de prevenção e promoção da saúde, visando o bem-estar de todos (LIMA et al, 2008; MINAYO; SOUZA, 1998). Além das formas de expressão da violência definidas na Lei Maria da Penha, considera-se também a presença de demandas clínicas, como indicadores indiretos de situações de violência (D'OLIVEIRA et al, 2009; MENEGHEL, 2015; MINAYO, 2006; WHO, 2002).

A saúde é uma das principais portas de entrada das mulheres em situação de violência na Rede de Atendimento de um município. As mulheres que sofrem/sofreram violência de gênero são usuárias mais frequentes e mais graves dos serviços de saúde, apresentando sequelas de saúde mental e física, tais como lesões, dor crônica, problemas gastrointestinais e ginecológicos (incluindo DST's), depressão e estresse pós-traumático. Em mulheres grávidas há indícios de prejuízos para a mãe e para o bebê. Se os danos causados são menos específicos, as mulheres podem recorrer aos serviços de atenção primária. Casos mais graves 
exigem serviços de urgência, atenção secundária e até terciária (AGOSTINI, 2015; CAMPBELL, 2002; GARCIA-MORENO, 2005; SCHRAIBER; D'OLIVEIRA, 1999).

A Estratégia de Saúde da Família (BRASIL, 2006a) pode ser um possível instrumento de intervenção, por estar presente na comunidade. Neste sentido, acredita-se que seja possível que as mulheres vítimas de violência de gênero sejam acolhidas e sintam confiança para relatarem seu sofrimento, devido ao tipo de vínculo mais facilmente estabelecido do profissional com os membros da família. As equipes da ESF são compostas por médicos, enfermeiros, auxiliares de enfermagem e agentes comunitários de saúde (ACS), mas na literatura nacional, encontramos poucos trabalhos a respeito da percepção da violência de gênero pelos/as ACS.

Algumas pesquisas com profissionais da saúde procuraram identificar as condutas dos mesmos diante dos casos de suspeita ou de violência familiar. Dos resultados, as autoras constataram que as ACS percebem a violência vivida pelas mulheres que procuram o serviço, porém não se sentem preparadas para agir, sentem insegurança, sem proteção e limitadas quanto à resolutividade dos casos. A falta de preparo técnico levam-nas a ter condutas diferentes e até opostas, baseadas no "bom senso". Muitas desconhecem os mecanismos legais e só conhecem a Lei Maria da Penha (BRASIL, 2006b) superficialmente (LIRA et al, 2012). A (in)visibilidade do fenômeno da violência devido ao fator cultural é também um dos grandes problemas que dificultam o atendimento adequado por parte dos profissionais da saúde. Os entraves são diversos: há profissionais que tem medo de tocar no assunto, considerando a notificação compulsória como denúncia, há quem não tenha capacitação para lidar com o tema, e há aqueles/as que não percebem as especificidades da violência acometida contra as mulheres - que não é só física - por ser uma violência invisibilizada no campo da saúde, bem como na sociedade de forma geral, muitas vezes relacionadas a questões de poder e de autoridade, entrelaçadas com desigualdades socioeconômicas (KIND et al, 2013; SCHRAIBER et al, 2009).

Por outro lado, tem-se que tomar o cuidado de não se tratar a violência como uma doença ou como um risco em saúde, orientando as mulheres sobre ações para "curar-se" .

A resistência em incorporar o social no campo da saúde também é discutida por Minayo (2007) e Schraiber e D'Oliveira (1999), apontando como a violência contra as mulheres se torna "imperceptível" ou invisibilizada nesse campo.

\section{Método de pesquisa}

A presente pesquisa, de caráter qualitativo, foi baseada nos pressupostos metodológicos da psicologia sócio histórica (BOCK, 2011) e nos princípios da epistemologia qualitativa de González Rey $(2011$, p. 4) que "se caracteriza pelo seu caráter construtivo/interpretativo, dialógico e pela sua atenção ao estudo dos casos singulares". 
O desenvolvimento da pesquisa ocorreu na Vila dos Pescadores, local indicado pela Secretaria Municipal de Saúde de Cubatão, por tratar-se da maior unidade de PSF do município, que contava com três equipes da ESF em funcionamento, além de ser considerado um bairro de alta vulnerabilidade social, com alto índice de pobreza, precariedade das condições de moradia, violência e exclusão social (CASTRO-SILVA et al, 2014). Cubatão caracteriza-se pela vulnerabilidade social de quase a metade de sua população, de acordo com o Índice Paulista de Vulnerabilidade Social - IPVS, 42,2\% da população exibe baixa condição socioeconômica: $21,2 \%$ da população no grupo Vulnerabilidade Alta e $21,0 \%$ no grupo Vulnerabilidade Altíssima (SÃO PAULO, 2012).

A VP é um território onde a desigualdade social é enorme, com muitas moradias do tipo palafitas construídas sobre o mangue "com graves implicações para a saúde e a vida de suas populações. Além do risco constante provocado por cheias da maré e desabamentos, há a ameaça da territorialidade do tráfico de drogas, favorecida pela morfologia e fragilidade social do lugar" (BRANDÃO et al, 2010, p. 9).

Através da observação participante, que ocorreu de março a dezembro de 2016, a pesquisadora acompanhou os/as ACS (e outros profissionais da ESF) em visitas domiciliares, para conhecer a realidade da comunidade, ir se familiarizando com o contexto em que a pesquisa ia acontecendo, como para também criar um vínculo mais próximo com os/as agentes. Ainda participou de reuniões com a equipe de saúde, bem como fez observações na própria UBS, além de interagir com os munícipes. Essa fase resultou na elaboração de 20 diários de campo (DC), sendo 16 escritos pela mesma e 4 construídos coletivamente, pelos alunos do grupo de pesquisa. Nos DC, a pesquisadora relatava o que observou, a partir de suas experiências, percepções e sentimentos despertados pelas vivências nos encontros.

O acompanhamento dos/as ACS em visitas diárias e em reuniões levantou o interesse da pesquisadora em realizar entrevistas abertas com duas ACS. A primeira entrevistada (ACS1) foi escolhida em função de sua história de vida relatada em um grupo, pois referiu que era uma mulher submissa ao marido, sofrendo violência psicológica e que conseguiu superar a dominação, tornando-se uma mulher com autoestima elevada. Era agente há oito anos, entrando inicialmente por indicação política, mas tornando-se posteriormente concursada. A segunda entrevistada (ACS2) foi escolhida por ter um papel de liderança na comunidade, tendo uma atuação mais direta em ações de empoderamento feminino, como um grupo de educação formal de mulheres analfabetas. É agente há mais de dez anos, porém não era concursada.

A epistemologia qualitativa de González Rey (2012) foi utilizada para analisar todo o processo de investigação, em dois momentos diferentes: 1) o processo de observação participante, através das informações qualitativas colhidas nos DC e nos encontros com os/as profissionais e munícipes; e 2) entrevistas abertas, com duas ACS; pois considera que a pesquisa de campo 
"é um processo permanente de estabelecimento de relações e de construções de eixos relevantes de conhecimento dentro do cenário em que pesquisamos o problema" (GONZÁLEZ REY, 2011, p.96).

O processo de observação participante permitiu conhecer detalhadamente a rotina do trabalho da equipe da ESF, em especial dos/as ACS, na sua relação com a comunidade, que levou à construção de três categorias empíricas como unidades de significação (GONZÁLEZ REY, 2011): 1) a comunidade; 2) a violência de gênero; 3 ) a organização do trabalho dos/as ACS. Neste artigo irei discutir apenas a segunda categoria devido a atender seu objetivo.

O projeto foi aprovado sob o Parecer Consubstanciado número 1.413.904 e CAAE 51988414.0.0000.5505, do Comitê de Ética em Pesquisa da Universidade Federal de São Paulo - Hospital São Paulo - UNIFESP-HSP. Assim sendo, todos os procedimentos éticos foram cumpridos segundo a Resolução Normativa 466/12 do CNS/MS, com a assinatura do Termo de Consentimento Livre e Esclarecido (TCLE) por parte dos participantes.

\section{Apresentação e discussão dos resultados}

Os resultados obtidos foram analisados pela categoria empírica "Violência de Gênero", segundo duas óticas: "ser mulher" e "a violência por parceiro íntimo" na Vila dos Pescadores. Algumas falas das agentes foram utilizadas para discutir a visão essencialista, universalista e homogênea sobre a mulher. A "naturalização" da violência na comunidade, denominada de violência "estrutural" por Minayo (2006), também foi problematizada, juntamente com o patriarcado enquanto discurso normativo articulado com o capitalismo, na busca de explicação da opressão das mulheres pelos homens.

\subsection{Ser "mulher" na Vila dos Pescadores}

Para Costa (1998), a categoria mulher é historicamente construída. Nicholson (2000) discute a categoria "mulher" a partir de semelhanças e diferenças que se cruzam, que também devem ser consideradas em relação ao momento histórico de determinada cultura. Já Piscitelli (2002) lembra que não se pode considerar uma universalização das características das mulheres, pois muitas estiveram no poder durante muitos anos, contrariamente às ideias dominantes da superioridade masculina.

A pesquisadora pôde perceber que algumas ACS ainda tem o conceito "ideal" de mulher como genérico e universal, em relação a como a mulher deve "ser", como deve "agir", que "lugar" que a mulher deve ocupar na sociedade. Palavras como "gente", "mulher mais velha", "as mais jovens", "elas", passam a noção de uma percepção homogênea de mulher, como se fossem iguais em emoções, pensamentos e comportamentos, como se tivessem a mesma essência: 
"[...] tem gente que engravida só pra agarrar o garoto! Às vezes na cabeça dela, ela ama, ela ama, ela ama [...]" (ACS1). "[...] E as mulher mais velha, não, por elas serem mais madura elas já sabem conduzir essa coisa do envolvimento emocional [...] E as mais jovens [...]" (ACS2). "[...] elas não pede ajuda, por ser safada, está acostumada a apanhar" (DC2).

Essas falas demonstram uma percepção por parte de várias ACS por muito sustentada em relação à categoria "mulher". Os historiadores sociais defendiam que haveria uma homogeneidade nas "mulheres", uma essência única que não se alterava, mesmo em contextos diversos, enquanto que o movimento feminista da época se apropriou do discurso de uma "identidade coletiva", mantendo uma postura de oposição "homens versus mulheres". Durante a trajetória da própria teoria e movimentos feministas, surgiram questionamentos e contradições - que permitiram o tensionamento de uma identidade comum, passando-se a pensar em múltiplas identidades e experiências de mulheres (NICHOLSON, 2000; SCOTT, 2005)

Então devemos compreender o termo 'mulher" como um sentido político (CASSAB, 2015; PEDRO, 2011), como uma emaranhada trama de características, considerando as semelhanças e diferenças na construção de práticas políticas de grupos constituídos, mesmo que transitoriamente (NICHOLSON, 2000).

Pode-se observar pelos relatos que há diferentes situações de mulheres na VP, exemplificando como essas "mulheres" não podem ser homogeneamente consideradas:

"Tem muita mulher separada, [...] elas são chefe de família" (ACS2). "[...] as mulheres tão trabalhando fora... muitas avós criando netos ... mais adolescentes, ou jovens, de 18 - 20 anos, levando crianças pro parquinho" (ACS1).

As falas acima, das ACS, são percepções a-históricas, sem nenhuma crítica em relação ao motivo, algumas mulheres dessacomunidade se comportam de determinada maneira. Veem a mulher como uma identidade única, sem considerar as diferenças de classe, raça, etnia, sexualidade e geração existentes na própria comunidade.

Uma outra situação que dificulta "ser mulher" na VP implica na ausência de equipamentos sociais de apoio às mães, sendo que há somente uma creche municipal para 40 crianças com até 2 anos de idade, insuficiente para uma população de quase 10 mil pessoas, em que 9,8 \% são crianças até 4 anos (IBGE, 2010):

"Há poucas creches da região por isso os filhos mais velhos, familiares, ou vizinhos ajudam a cuidar. A creche daqui é só para crianças até 2 anos" (DC20). 
Essa fala expressa a solidariedade entre as mulheres com a ajuda de vizinhas no cuidado dos filhos cujas mães trabalham fora, devido à ausência do Estado e/ou da paternidade não exercida por muitos homens. A rede de apoio entre as mulheres pobres está situada dentro de uma espécie de rede de proteção perante as inseguranças sociais de dada realidade de vulnerabilidade social (AZEREDO, 2010).

Mas mesmo assim, muitas mães ficam impedidas de trabalhar, como testemunha com sua história a ACS1. Ela própria também relatou ter tido diversos filhos, o que a impediu de trabalhar fora e ter sua independência financeira:

"[...] eu fui engravidando um atrás do outro, fui engravidando. Só que na época, na minha cabeça, meu marido me amava, que queria formar família, e não, estava era me prendendo o tempo todo, eu não podia trabalhar. Quando eu pensava que eu pudia trabalhar, eu não podia porque eu tinha filho pequeno pra cuidar" (ACS1).

Nessa fala, pode-se observar que um outro aspecto de controle dos homens sobre as mulheres é a maternidade. Essa responsabilização da mulher sobre a procriação e cuidado dos filhos aparece também em outros discursos, pois as relações homem e mulher resultam de construções sociais e políticas de teorias e visões a respeito do lugar de cada um, cabendo às mulheres "por natureza" a reprodução, cuidados com o lar e a educação dos filhos, enquanto que os homens pertencem às esferas públicas e ao poder, devido à suposta "natureza masculina" (AGUIAR, 2015; MATOS, 2015).

Algumas agentes também explicitaram que, embora muitas mulheres sejam as principais provedoras financeiras da casa, os homens ainda são reconhecidos como o "chefe" da casa, mesmo estando desempregados (DC13, ACS2). Muitas delas nem têm consciência do processo de aprendizagem social que reforça as representações simbólicas de uma ordem social sexista, que permeiam seus comportamentos e atividades na manutenção da sujeição aos homens (AGUIAR, 2015).

Nos relatos das entrevistadas, observou-se que a situação de algumas mulheres na VP melhorou a partir do momento em que elas têm um trabalho:

\footnotetext{
"Hoje em dia 'tá mais fácil eu acredito a vida das mulheres, as mulheres tão trabalhando fora... mais... antes era mais difícil, hoje em dia é bem mais fácil [...] É ... mulheres trabalhando mais, mais independentes, separando do esposo, tendo sua casinha, construindo sua casinha de madeira bem pequenininha, mas construindo" (ACS1).
}

Mas mesmo trabalhando, os salários mais baixos que as mulheres recebem em atividades iguais, a responsabilidade maior da mulher no cuidado das tarefas da casa, com a educação dos filhos, pais e/ou parceiros indicam a desigualdade na valorização da força de trabalho feminina, que juntamente com a violência de gênero, apontam ainda a presença do patriarcado na nossa 
sociedade contemporânea (AGOSTINI, 2015; AGUIAR, 2015; HENNINGTON; MORENO, 2015; ROMANI, 2015).

A ideologia do patriarcado, internalizada por homens e mulheres através da educação desde crianças, legitima que os homens têm poder total sobre a mulher, devendo essa lhe ser submissa, fazendo uso da violência, se necessário (ARAÚJO, 2008). As mulheres estabelecem formas de resistências a essa dominação, porém nem sempre suficientes para deter a violência contra elas (ARAÚJO, 2008; SAFFIOTI, 2001; 2004).

Também temos que considerar o conceito de violência simbólica proposto por Bordieu (2016), no qual se compreende que a linguagem homogeneíza o pensamento dos diferentes atores sociais, sobretudo exercido pelo Estado, através de várias instituições, principalmente da educação. A escola transmite os conteúdos culturais da classe dominante, sendo reproduzidos pelos educandos sem crítica, reforçando a dominação.

\subsection{A violência por parceiro íntimo na Vila dos Pescadores}

No Brasil temos tido avanços a nível jurídico, mas a aplicação das leis ainda encontra problemas, pois demandas sociais relacionadas à violência de gênero foram sendo institucionalizadas (MENEGHEL et al, 2011; SANTOS, 2008). Mesmo com a promulgação da Lei Maria da Penha em 2006 (BRASIL, 2006b; SANTOS, 2008) e da Lei 13.104, de 9 de março de 2015 que torna o feminicídio crime hediondo (BRASIL, 2015), a taxa de homicídios contra mulheres aumentou em $11,6 \%$ no período de 2004 a 2014. Isso significa que não basta enfrentar a violência contra a mulher apenas a nível jurídico, pois o problema não se resolve somente com a punição dos agressores por meio de leis. Mesmo com a promulgação das leis Maria da Penha e do Feminicídio, além de todos os esforços em se formular as demais políticas voltadas ao enfrentamento da violência, há uma complexidade para enfrentar esse tipo de violência que perpassa por obstáculos - culturais e políticos - a serem superados para acabar com mais essa tragédia nacional (IPEA, 2016).

No primeiro contato da pesquisadora com os/as ACS, quando explicado o objetivo de pesquisa, a maioria confirmou a existência da violência de gênero, mas que sobre isso nada pode ser falado: "pois o agressor ameaça a própria mulher se ela falasse alguma coisa" (DC2).

Esse tipo de situação tornou-se mais grave quando foi observado que a relação de violência se perpetua. Naquela mesma reunião, algumas ACS manifestaram que não compreendem porque várias mulheres vítimas de violência de gênero continuam na relação com o agressor, culpabilizando-as pela sua situação:

"[...] elas não pedem ajuda, por ser safada, está acostumada a apanhar" (DC2). 
Nessa fala, configura-se um deslocamento do discurso (muitas vezes repetindo o discurso 'dominante'), responsabilizando a vítima, considerada como uma 'autora passiva', quando sofre agressões: "A postura sexista, discriminatória e infame, esteve presente por décadas no próprio código penal. O modelo defensivo reabilita essa velha prática misógina estigmatizante" (SOARES, 2002, p. 25). Esse mesmo autor considera como outros aspectos da retórica defensiva [masculina]: o desprezo, a humilhação e a desqualificação da vítima. Essa retórica defensiva pode ser vista nas frases populares: "a mulher está apanhando porque merece; fez alguma coisa errada ou, se não fez, com certeza vai fazer" (MINAYO, 2015), "mulher gosta de apanhar" (LEAL, 2015), justificando, naturalizando e banalizando a violência de gênero contra a mulher.

Além da visão acima, outros/as agentes têm diferentes entendimentos sobre os motivos da mulher continuar em uma relação abusiva:

“Então eu acho que a mulher, aqui, ela aceita! Então tem ... medo, de ter que trabalhar, por medo de não conseguir sobreviver..., medo de ficar sozinha..., eu acho que é o medo [...] Mas a mulher, aceita essa situação, então o homem vai avançando, é a mesma coisa da violência" (ACS2).

"[...] muitas não se sentiam no direito de sair, de questionar o companheiro. Comentamos sobre a baixa autoestima destas mulheres, que muitas vezes repetiam a vivência de seus pais" (DC11).

"Na verdade, algumas querem, que amam, acham que a pessoa vai mudar por amor e depois volta a fazer a mesma coisa. Outras vezes é por causa que não trabalha e o marido que trabalha, sustenta, ou porque os filhos precisam, por aí vai, sempre uma desculpa que a pessoa vai ter" (ACS1).

Pode-se usar o modelo explicativo denominado "ciclo da violência" para compreender os exemplos acima relatados (MENEGHEL, 2015). Como o próprio nome diz - ciclo da violência -, refere-se a episódios repetitivos de violência caracterizados por momentos de "tensão", "violência" e "reconciliação".

A fase de tensão caracteriza-se mais por violência psicológica, como intimidações, abusos verbais, culpabilização da mulher por não cumprir suas "funções domésticas". A mulher, amedrontada, acaba cedendo, mantendo a submissão ao homem. A segunda fase - de violência - é quando o homem chega à agressões físicas e verbais intensas, provocando muito medo na vítima. $\mathrm{Na}$ fase de reconciliação, o homem mostra arrependimento, prometendo mudar seu comportamento, mostrando-se carinhoso, prometendo que não mais vai ser agressivo.

Infelizmente esse ciclo tende a se repetir em intervalo de tempo cada vez menor e em intensidade maior, podendo chegar ao feminicídio. Em um estudo de Sagot (2000) sobre as dificuldades das mulheres de saírem das relações 
violentas, foram identificados fatores inibidores e facilitadores, chamado de Rotas Críticas, por serem longas, extenuantes, repetitivas e ineficazes. Verificou-se que a rota se inicia quando resolvem romper o silêncio e fazer a denúncia, mas antes disso precisam aceitar que estão sofrendo algum tipo de violência (MENEGHEL et al, 2011).

Fatores que facilitam o abandono (ou a fuga) de relações abusivas dependem de atitudes pessoais, como: o cansaço em ser humilhada, a indignação pela violência contra os filhos, a percepção do aumento do risco de vida. Já os motivos que dificultam o rompimento são: o medo, os sentimentos de culpa e de vergonha, a postura familiar conservadora, e as limitações econômicas. Muitas mulheres não denunciam porque foram socializadas a encarar como natural que a violência seja usada como uma forma de resolução de conflitos nas relações familiares (BIGLIA; SAN MARTIN, 2007), como conflito do casal que deve ser mantido a nível privado (LEAL, 2015). Quando começam a relatar a violência sofrida, geralmente o fazem para pessoas da família ou amigas. Porém nem sempre encontram apoio, principalmente quando os familiares têm concepções tradicionais em relação à gênero. As famílias podem ter uma atitude contraditória entre estimular ou em ser contrária à separação do casal.

$\mathrm{Na}$ VP, em algumas situações, as famílias e outras pessoas assistem passivamente, não se envolvendo, como cumprindo o ditado "em briga de marido e mulher, não se mete a colher", como exemplificado pela mesma agente, em duas diferentes situações:

"[...] porque essa menina que desapareceu, eu não tava aqui na época. [...] ela foi levada pela rua, todo mundo viu, todo mundo sabia, o que podia acontecer com ela e ninguém impediu, ninguém tomou a frente. [...] a família dela, tia, tio, prima, tinha uma família muito grande e ninguém, ninguém se manifestou!" (ACS2).

"[...] Ela tem família esclarecida, formada, a família dela é uma família conceituada! Não é família assim ... ignorante, sem conhecimento de nada. Não, tanto que a família dela já não se envolve mais. Porque tentou e não conseguiu" (ACS2).

Na Vila dos Pescadores, o envolvimento da família pode ser um pouco mais complicado, pois algumas vezes a decisão de castigar a mulher parte do "tribunal do tráfico", quando há uma queixa, geralmente de um homem. O "tribunal do tráfico" refere-se aos traficantes "líderes" que impõe regras de conduta na comunidade, tendo formas diferentes de punir as traições conjugais, quando se trata de homem ou de mulher. As mulheres têm seus cabelos cortados e também podem apanhar com um pedaço de madeira com pregos. Se é o homem quem trai a mulher, também apanha e é expulso da comunidade. Dependendo da gravidade do caso, ele é levado de barco e desaparece (DC2; CASTRO-SILVA, 2011). 
Além da violência física, também ocorre a "violência psicológica", na VP: "há também a agressão verbal, com xingamento e falta de respeito" (DC2). Outro exemplo de violência psicológica contra a mulher relatado, é que ela, em caso de separação, tem que esperar de 3 a 6 meses, pela autorização do ex-companheiro para que possa ter um novo relacionamento:

"[...] o homem permitia um 'luto de 3 ou 6 meses', isto é, ela somente poderia arrumar outro homem após 3 ou 6 meses da separação" (DC2).

"[...] a mulher aqui ela não pode namorar, ter esta liberdade de escolha. Ela escolheu um parceiro, é aquele parceiro. Se ela quiser se separar daquele [...] ela tem que enfrentar uma série de dificuldades, dependendo do prazo,[...] uns 3 meses ou é 6 meses [...] Pra poder ela ter outro parceiro[...] E se ela sair por aí durante, dependendo de quem é o parceiro, ela pode até morrer. Ela paga com vida" (ACS2).

Para não morrer, algumas mulheres têm que fugir da comunidade, mesmo que haja só suspeita de que esteja envolvida com outro homem, pois nem a família consegue protegê- las:

"Houve umas conversas paralela que ela tava com outra pessoa e ela teve que sair, pra não morrer, com medo, né, porque não tem proteção, não tem como [...] as famílias também ficam meio refém desta situação toda" (ACS2).

Quando a mulher consegue a liberdade através da ajuda do "tribunal", se ela voltar atrás, não consegue mais apoio depois:

"Ela queria se separar! [...] Eu só sei que depois de muitas idas e vindas, muita confusão, ela conseguiu a liberdade [...] Ele foi [...] sentenciado e condenado: 'Você não pode chegar perto daquela mulher'. Senão ele sofria as consequências [...] Aí foi 'aquele homem bonzinho'[...] ele foi muito ardiloso! [...] Até que ela cedeu. Quando ela cedeu, ela perdeu o direito dela, de proteção. E ele ganhou o direito de ter aquela mulher de volta" (ACS2).

A ACS2 mostra que tem certo conhecimento de que há outras diferentes formas de opressão sobre as mulheres, desde definir o que ela deve vestir, o que ela pode ou não fazer e até o que comer. E muitas vezes o homem se acha muito bom, por permitir que ela trabalhe:

"Ela não tem direito a vestir o que ela quer, ela não tem o direito a fazer o que ela quer, ela não tem direito a conversar com quem ela quer. Nem a comer, onde ela quer ir, ela não tem mais liberdade! [...] E ele acha assim, que ele é um marido maravilhoso, porque ele deixa ela trabalhar [...] ele tenta dar uma vida legal pra ela. [...] Mas ele oprime ela de uma forma que ela é refém! " (ACS2). 
Na percepção da ACS2, a violência de gênero tem diminuído na VP, mesmo que lentamente:

"Eu acho que a violência já foi maior, pra mulher, já foi maior! A mulher hoje, ela, muito lenta, lentamente, mas ela se impõe, ela se impõe mais do que no passado [...] A gente vê isso quando a gente faz reuniões. [...] Na comunidade. A participação da muIher ainda é menos ... do que a participação do homem".

As percepções das ACS apresentadas aqui, apontam o cuidado que se deve ter com a banalização da violência, pois muitas falas reforçam a cultura da supremacia masculina, a "naturalização" da associação entre pobreza e violência (NJAINE, 2015), com a "aceitação" de regras de relacionamentos impostas por indivíduos e grupos violentos, como os traficantes na VP.

As falas das ACS demonstram de uma forma geral, como não há um preparo para tratar sobre o tema, pois muitas apontam para concepções valorativas, arraigadas na sociedade, reproduzidas por profissionais que poderiam ter outra postura caso tivessem capacitações adequadas para lidar com o tema. Quando se fala em políticas públicas, a formação dos profissionais é um ponto fundamental para romper com a forma como a violência é naturalizada do ponto de vista, inclusive, institucional.

\section{Considerações finais}

Todos os relatos apresentados de ACS reafirmam que a violência contra as mulheres é algo naturalizado na sociedade. Fica claro que as profissionais não possuem capacitação para identificar as especificidades e complexidade do tema.

Quando se discute sobre violência, não podemos desconsiderar que a violência é uma forma de domínio econômico e político das classes dominantes, através de uma ideologia neoliberal que coloca a culpa nos indivíduos. Para melhor compreender o fenômeno da violência, somente uma abordagem intersetorial e interdisciplinar é capaz de abarcar essa problemática, através da integração dos saberes das ciências sociais, da epidemiologia e da psicologia, sem desconsiderar os aspectos biológicos. Algumas teorias sobre a violência são reducionistas, pois colocam como padrão de normalidade as regras da classe dominante, não considerando a violência que aparece naturalizada, tanto a nível estrutural, do Estado, quanto a violência cultural.

A pouca eficácia dos serviços de saúde no atendimento às vítimas de violência, em todos os níveis, tem como uma das causas a visão parcial da doença do usuário, enxergando tão somente o corpo físico, do ponto de vista biomédico, sem qualquer vislumbre à violência em si e futuras consequências. Esse modo de proceder medicalizando as questões cotidianas, afasta o componente social de qualquer problema, considerando e tratando apenas os aspectos médicos e de diagnóstico mais comprovável. 
A pesquisa permitiu analisar como Agentes Comunitárias de Saúde têm percepções essencialistas e naturalizadas sobre o papel da mulher na sociedade e sobre as formas de violência. Não percebem grande parte da violação de seus direitos, acabando por repetir discursos que desqualificam e perpetuam a mulher (historicamente) em uma posição inferior desigual que pode "justificar" a sua vulnerabilidade à violência. Neste sentido, as ACS precisam receber uma melhor formação para que possam tornarem-se mais conscientes de que a violência de gênero é uma violação dos direitos humanos, de forma a atuarem nas questões sociais que estão na base do problema, para não atuarem somente a nível individual. É necessário que extrapolem a visão biomédica e atuem sobre os determinantes sociais da saúde.

Mas essa não é uma responsabilidade a mais a ser colocada "nas costas" dos agentes, pois é um pressuposto da atuação dos profissionais dos diferentes serviços que compõem as redes de atendimento às mulheres em situação de violência. Por exemplo, é parte das atribuições dos profissionais de saúde a notificação compulsória ao SINAN em casos de violência contra a mulher, o que é mais um motivo para que devam saber reconhecer situações de violência.

Fazer com que a violência seja conhecida e reconhecida no interior dos serviços de saúde é passo crucial para que seja compreendida e, portanto, um tratamento intersetorial adequado e integral possa ser prestado aos usuários. A abordagem da violência pelo setor da saúde deve passar pelas orientações da Política Nacional de Promoção de Saúde, divulgada desde 2006. O problema da violência de gênero não pode ser restrito a ações isoladas, mas devem resultar em ações articuladas a nível de saúde, justiça, segurança pública e trabalho, assim como o envolvimento da sociedade civil.

Preconiza-se potencializar as intervenções aplicadas na questão da violência, tomando a atenção primária de um ponto de vista integral. Tanto pelo reconhecimento da violência em sua complexidade, desestimulando o seu surgimento, como no tratamento mais amplo e profundo de suas consequências. Além disso, integral também, porque a própria vítima dessa violência deve ser ouvida e levada em consideração em relação às intervenções recomendadas.

Também fundamental para a prevenção da violência é o trabalho desenvolvido a partir dos princípios do PAISM (Programa de Atenção Integral à Saúde da Mulher), com a busca do empoderamento das mulheres, a emancipação dos trabalhadores e usuários dos serviços, valorizando os direitos reprodutivos, sexuais e o trabalho com os conflitos de gênero.

Este estudo mostrou que se deve "meter a colher" na violência de gênero, pois uma vida emancipada e sem violência passa por políticas públicas que garantam a conquista dos direitos a trabalho, moradia, creche, educação, direitos humanos que devem ser divulgados pelos profissionais, além da divulgação da rede intersetorial que cuida da violência, de forma a minimizar a vulnerabilidade dos munícipes de toda a comunidade estudada. 
A VIOLÊNCIA DE GÊNERO CONTRA A MULHER NA

PERCEPÇÃO DE AGENTES COMUNITÁRIOS DE SAÚDE

Ciente das limitações deste estudo, espera-se que este artigo contribua a partir da demonstração de que há importantes aspectos culturais que influenciam na percepção e nos sentidos das ACS sobre a violência contra as mulheres, que podem inclusive impactar na sua forma de atuação em relação às mulheres que vivenciam violência na comunidade estudada. Em se tratando de políticas públicas, este é um ponto importante a ser considerado, tendo em vista que uma vida emancipada e sem violência perpassa ao direito a um atendimento adequado pelos diferentes profissionais dos serviços que compõem as redes de atendimento, tal qual o serviço de saúde em que se integram as/os agentes comunitários estudados.

\section{Referências}

AGOSTINI, M. Agravos à Saúde decorrentes da Violência. In: FLEURY-TEIXEIRA, E; MENEGHEL, SN (orgs). Dicionário Feminino da Infâmia. Rio de Janeiro: FIOCRUZ, 2015, p. 28-30.

AGUIAR, NF. Patriarcado. In: FLEURY-TEIXEIRA, E; MENEGHEL, SN (orgs). Dicionário Feminino da Infâmia. Rio de Janeiro: FIOCRUZ, 2015, p. 270-272.

ARAÚJO, MF. Gênero e violência contra a mulher: o perigoso jogo de poder e dominação. Psicología para América Latina; 14, 2008. Disponível em: http://pepsic.bvsa- lud.org/scielo.php?script=sci_arttext\&pid=S1870350X2008000300012. Acesso em: 19/06/2015.

AZEREDO, VG. Entre paredes e redes: o lugar da mulher nas famílias pobres. Serv. Soc. Soc, São Paulo, n. 103, p. 576-590, 2010. Disponível em: http://www.scielo.br/pdf/sssoc/n103/a09n103.pdf. Acesso em 08/10/2016.

BANDEIRA, L M; ALMEIDA, T M C. Vinte anos da Convenção de Belém do Pará e a Lei Maria da Penha. Revista Estudos Feministas, 23(2), 501-517, 2015 . Disponível em: http://www.scielo.br/scielo.php?script=sci_ arttext\&pid=S0104- 026X2015000200501\&lng=en\&nrm=iso. Acesso em: 23/07/2017.

BIGLIA B, SAN MARTIN C. Estado De Wonderbra. Entretejiendo narraciones feministas sobre las violencias de género. Barcelona: Virus Editorial; 2007. Disponível em: https://www.academia.edu/313054/Estado_De_ Wonderbra._Entretejiendo_narraciones_fe-ministas_sobre_las_violencias_de_g\%C3\%A9nero. Acesso em: 07/03/2017.

BOCK, AMB. A Psicologia Sócio-Histórica: uma perspectiva crítica em psicologia. In: BOCK, AMB.; GONÇALVES, MGM; FURTADO, O. (orgs) Psicologia Sócio-Histórica: uma perspectiva crítica em psicologia. 5a ed. São Paulo: Cortez, 2011, p. 15-35

BOURDIEU, P. A dominação masculina. Rio de Janeiro: Bestbolso, 2016. (Original publicado em 1998).

BRANDÃO, MVM; MORELL, MGG; FONTEBASSO NETO, J; FERREIRA, MC. Um Estudo das Desigualdades na Região Metropolitana da Baixada Santista: Suas Dimensões Socioespaciais. Anais do XVII Encontro Nacional de Estudos Populacionais, ABEP, realizado em Caxambu, MG, Brasil. Santos, SP: Leopoldianum, Universidade Católica de Santos e ESC, 2010. Disponível em: http://www.abep.nepo.unicamp.br/encontro2010/docs_ pdf/eixo_2/abep2010_2101.pdf. Acesso em: 11/11/2016.

BRASIL. Ministério da Saúde. Política Nacional de Redução da Morbimortalidade por Acidentes e Violência. Portaria GM/MS no 737, de 16 de maio de 2001. Diário Oficial da União no 96, seção 1e, de 18 de maio 2001. Disponível em: http://www.prefeitura.sp.gov.br/cidade/secretarias/upload/portaria737_1254487650.pdf. Acesso em: 23/03/2016

BRASIL. Ministério da Saúde. Lei 10.778, de 24 de novembro de 2003. Estabelece a notificação compulsória, no território nacional, do caso de violência contra a mulher que for atendida em serviços de saúde públicos ou privados Brasília. Disponível em: http://www.planalto.gov.br/ccivil_03/leis/2003/L10.778.htm. Acesso em: 31/10/2016.

BRASIL. Ministério da Saúde. Secretaria de Atenção à Saúde. Departamento de Atenção Básica. Política nacional de atenção básica. Brasília: Ministério da Saúde, 2006a. Disponível em: http://dab.saude.gov.br/portaldab/ 
pnab.php. Acesso em: 22/09/2016.

BRASIL. Casa Civil. Subchefia para Assuntos Jurídicos. Presidência da República. Lei no 11.340, de 7 de agosto de 2006. Diário Oficial da União, de 7 de agosto de 2006b. Brasília. Disponível em: http://www.planalto.gov. br/ccivil_03/_ato2004-2006/2006/lei/111340.htm. Acesso em:23/09/2016.

BRASIL. Lei 13.104. Diário Oficial da União de 9 de março de 2015. Brasília. Disponível em: http://www.planalto.gov. br/ccivil_03/_Ato2015-2018/2015/lei/L13104.htm. Acesso em: 22/09/2016.

BUTLER, J. Cuerpos que importan. Sobre los límites materiales y discursivos del "sexo". 1a ed. Buenos Aires: Paidós, 2002.

BUTLER, J. Problemas de gênero: feminismo e subversão da identidade. 12a ed. Rio de Janeiro: Civilização Brasileira, 2016. (Original publicado em 1990).

CAMPBELL JC. Health consequences of intimate partner violence. Lancet, 359(9314):1331-1336, 2002. Disponível em: http://www.thelancet.com/pdfs/journals/lan- cet/PIIS0140-6736(02)08336-8.pdf. Acesso em: 20/06/2016.

CASSAB, LA. Mulher. In: FLEURY-TEIXEIRA, E; MENEGHEL, SN (orgs). Dicionário Feminino da Infâmia. Rio de Janeiro: FIOCRUZ, p. 239-240, 2015.

\section{CASTRO-SILVA, CR. A Potência de Ação de Agentes Comunitários de Saúde na Estratégia de Saúde da Família da Vila Dos Pescadores no Município de Cubatão. Relatório Edital MCT/CNPq 14/2011 (mimeo).}

CASTRO-SILVA, CR; MENDES, R; MORAES, RCP; ANHAS, DM; ROSA, KRM. Participação Social e a Potência do Agente Comunitário de Saúde. Psicologia \& Sociedade, 26 (n. spe. 2), 113-123, 2014. Disponível em: http://www.scielo.br/scielo.php?script=sci_arttext\&pid=S0102-71822014000600012 Acesso em: $11 / 11 / 2016$.

COLE, TB. Is Domestic Violence Screening Helpful? JAMA, 2000; 284(5):551-553, 2000. https://www.ncbi.nlm.nih. gov/pubmed/10918685. Acesso em 18/06/2016.

COSTA, CL. O tráfico do gênero. Cadernos Pagu, 11: 127-140, 1998. https://periodicos.sbu.unicamp.br/ojs/index.php/ cadpagu/article/view/8634468. Acesso em: 01/03/2017.

D'OLIVEIRA, AFPL; SCHRAIBER, LB; HANADA, H; DURAND, J. Atenção Integral À saúde de mulheres em situação de violência de gênero - uma alternativa para a atenção primária em saúde. Ciência: Saúde Coletiva, 14(4): 1037-1050, 2009. Disponível em: http://www.scielo.br/pdf/csc/v14n4/a06v14n4.pdf. Acesso em: 20/06/2015.

GARCIA-MORENO, G. Dilemmas and opportunities for an appropriate health-service response to violence against women. Lancet, volume 359, p. 1509-1514, 2005. https://www.ncbi.nlm.nih.gov/pubmed/11988263. Acesso em 15/05/2016.

GOMES, NP; DINIZ, NMF; SILVA FILHO, CC; SANTOS, JNB. Enfrentamento da violência doméstica contra a mulher a partir da interdisciplinaridade e intersetorialidade. Rev. enferm. UERJ, Rio de Janeiro, 2009 jan/mar; 17(1):14-7, 2009. Disponível em: http://www.facenf.uerj.br/v17n1/v17n1a03.pdf. Acesso em: 09/04/2016.

GONZÁLEZ REY, FL. Pesquisa qualitativa em Psicologia: caminhos e desafios. São Paulo: Cengage Learning, 2011.

GONZÁLEZ REY, FL. O social como produção subjetiva: superando a dicotomia indivíduo-sociedade numa perspectiva cultural-histórica. ECOS - Estudos Contemporâneos da Subjetividade, 2(2), 167-85, 2012. Disponível em: http://www.uff.br/periodicoshumanas/index.php/ecos/article/view/1023. Acesso em: 18/09/2016.

HENNINGTON, E; MORENO, E. Trabalho das mulheres. In: FLEURY-TEIXEIRA, E; MENEGHEL, SN (orgs). Dicionário Feminino da Infâmia. Rio de Janeiro: FIOCRUZ, 2015, p. 346-348.

IANNI, OCTÁVIO. Tipos e mitos do pensamento brasileiro. Sociologias, (7), 176-187, 2002. Disponível em: http:// www.scielo.br/scielo.php?script=sci_arttext\&pid=S1517- 45222002000100008. Acesso em: 13/07/2016.

IBGE - Instituto Brasileiro de Geografia e Estatística. (2010). Censo 2010. Disponível em: http://censo2010.ibge.gov.br/ sobre-censo.html. Acesso em: 17/11/2014.

IPEA - Instituto De Pesquisa Econômica Aplicada e Fórum Brasileiro de Segurança Pública. Atlas da Violência 2016. Brasil. Ministério do Planejamento, Orçamento e Gestão. Nota Técnica no 17, 2016. Disponível em: http:// www.ipea.gov.br/portal/images/stories/PDFs/nota_tecnica/160322_nt_17_atlas_da_v iolencia_2016_ finalizado.pdf. Acesso em: 01/11/2016. 
A VIOLÊNCIA DE GÊNERO CONTRA A MULHER NA

PERCEPÇÃO DE AGENTES COMUNITÁRIOS DE SAÚDE

KIND, Luciana. et al. Subnotificação e (in)visibilidade da violência contra mulheres na atenção primária à saúde. Cad. Saúde Pública, Rio de Janeiro, 29(9), p.1805-1815, 2013. Disponível em: http://www.scielo.br/scielo. php?pid=S0102-311X2013000900020\&script=sci_abstract\&tlng=pt .Acesso em 23/07/2017.

LEAL, SMC. Conflitos entre parceiros íntimos. In: FLEURY-TEIXEIRA, E, MENEGHEL, SN (orgs). Dicionário Feminino da Infâmia. Rio de Janeiro: FIOCRUZ, 2015, p. 63-65.

LIMA, DC; BÜCHELE, F; CLÍMACO, DA. Homens, Gênero e Violência Contra a Mulher. Saúde Soc. São Paulo, v.17, n.2, p. 69-81, 2008. Disponível em: http://www.sci- elo.br/scielo.php?script=sci_ arttext\&pid=S0104-12902008000200008. Acesso em: 06/06/2016.

LIRA, CEPR; SILVA, PPAC; TRINDADE, RFC. Conduta dos agentes comunitários de saúde diante de casos de violência familiar. Rev. Eletr. Enf. [Internet]. 14(4): 928-36, 2012. Disponível em: https://www.fen.ufg.br/fen_revista/ v14/n4/pdf/v14n4a22.pdf. Acesso em 14/07/2016.

MARTINS, A.P.A.; CERQUEIRA, D.; MATOS, M.V.M. A institucionalização das políticas públicas de enfrentamento à violência contra as mulheres no Brasil (versão preliminar). NT no13 IPEA. Brasília, 2015. Disponível em: https://www12.senado.leg.br/institucional/omv/entenda-a-violencia/pdfs/a- institucionalizacao-daspoliticas-publicas-de-enfrentamento-a-violencia-contra-as- mulheres-no-brasil. Acesso em: 23/07/2017.

MATOS, M. Construção social de gênero. In: FLEURY-TEIXEIRA, E; MENEGHEL, SN (orgs). Dicionário Feminino da Infâmia. Rio de Janeiro: FIOCRUZ, 2015, p. 68-71.

MENEGHEL, SN. Ciclo da Violência. In: FLEURY-TEIXEIRA, E; MENEGHEL, SN (orgs). Dicionário Feminino da Infâmia. Rio de Janeiro: FIOCRUZ, 2015, p. 61-63.

MENEGHEL, SN. Efeitos Emocionais das Violências de Gênero. In: FLEURY- TEIXEIRA, E; MENEGHEL, SN (orgs). Dicionário Feminino da Infâmia. Rio de Janeiro: FIOCRUZ, 2015, p. 115-117.

MENEGHEL, SN. Femicídio/Feminicídio. In: FLEURY-TEIXEIRA, E; MENEGHEL, SN (orgs). Dicionário Feminino da Infâmia. Rio de Janeiro: FIOCRUZ, 2015, p. 148-149.

MENEGHEL, SN et al. Rotas críticas de mulheres em situação de violência: depoimentos de mulheres e operadores em Porto Alegre, Rio Grande do Sul, Brasil. Cad. Saúde Pública, Rio de Janeiro, 27(4):743-752, 2011. Disponível em: http://www.scielo.br/scielo.php?pid=S0102 311X2011000400013\&script=sci_abstract\&tlng=pt. Acesso em: 11/02/2017.

MINAYO, MSC; SOUZA, ER. Violência e saúde como um campo interdisciplinar e de ação coletiva. História, Ciências, Saúde - Manguinhos, IV(3): 513-531, 1998. Disponível em: http://www.scielo.br/pdf/hcsm/v4n3/v4n3a06. Acesso em 13/07/2016.

MINAYO, MSC. Violência e Saúde. Rio de Janeiro: FIOCRUZ, 2006.

MINAYO, Maria Cecília de Souza. A inclusão da violência na agenda da saúde: trajetória histórica. Ciência \& Saúde Coletiva, 11 (Sup), p. 1259-1267, 2007. Disponível em: http://www.scielo.br/scielo.php?script=sci_ arttext\&pid=S1413-81232006000500015. Acesso em 24/07/2017.

MINAYO, MCS. Determinantes Sociais da Violência. In: FLEURY-TEIXEIRA, E; MENEGHEL, SN (orgs). Dicionário Feminino da Infâmia. Rio de Janeiro: FIOCRUZ, 2015, p. 91-93.

MOORE, HL. Compreendendo Sexo e Gênero. Tradução de Júlio Assis Simões para uso didático (mimeo). Do original em inglês: "Understanding sex and gender", in Tim Ingold (ed.), Companion Encyclopedia of Anthropology. Londres, Routledge, p. 813-830, 1997.

NJAINE, K. Banalização da violência. In: FLEURY-TEIXEIRA, E; MENEGHEL, SN (orgs). Dicionário Feminino da Infâmia. Rio de Janeiro: FIOCRUZ, 2015, p. 54.

NICHOLSON, L. Interpretando o gênero. Revista Estudos Feministas, 8(2); 8-41, 2000. Disponível em: https:// periodicos.ufsc.br/index.php/ref/article/view/11917. Acesso em: 02/03/2017.

OBSERVE. Observatório da Lei Maria da Penha. Condições para aplicação da Lei 11.340/2006 (Lei Maria da Penha) nas Delegacias Especializadas de Atendimento à Mulher (Deams) e nos Juizados de Violência Doméstica e Familiar nas capitais e no Distrito Federal (Relatório técnico). 2010. Disponível em: http://www.Observe.ufba.br/_ARQ/Relatorio\%20apresent\%20e\%20DEAMs.pdf. Acesso em: 10/08/2016

PASINATO, W. Oito anos de Lei Maria da Penha. Entre avanços, obstáculos e desafios. Revista Estudos Feministas, 
23(2), 533-545, 2015. Disponível em: https://periodicos.ufsc.br/index.php/ref/article/view/38874. Acesso em: $25 / 07 / 2017$.

PISCITELLI, A. "Re-criando a (categoria) mulher?" In: Agranti, L.M. (org) A prática feminista e o conceito de gênero. Campinas: IFCH/Unicamp, 2002. Disponível em: http://www.culturaegenero.com.br/download/ praticafeminina.pdf. Acesso em 19/02/2017.

ROMANI, JP. Assimetria de gênero. In: FLEURY-TEIXEIRA, E; MENEGHEL, SN (orgs). Dicionário Feminino da Infâmia. Rio de Janeiro: FIOCRUZ, 2015, p. 42-43.

SAFFIOTI, H.I.B. Contribuições feministas para o estudo da violência de gênero. Cad. Pagu, 16, Campinas, 2001. Disponível em: http://www.scielo.br/pdf/cpa/n16/n16a07.pdf. Acesso em: 20/08/2015.

SAFFIOTI, HIB. Gênero, patriarcado, violência. São Paulo: Perseu Abramo, 2004.

SANTOS, CM. Da Delegacia da Mulher à Lei Maria da Penha: lutas feministas e políticas públicas sobre violência contra mulheres no Brasil. Coimbra: Centro de Estudos Sociais, Universidade de Coimbra. (Oficina, 301), 2008. Disponível em: http://www.ces.uc.pt/publicacoes/oficina/ficheiros/301.pdf. Acesso em: 10/08/2016

SÃO PAULO. Secretaria de Desenvolvimento Social. Mapa Da Ação Social, 2012. Disponível em: http://www. desenvolvimentosocial.sp.gov.br/. Acesso em: 14/02/2016.

SCHRAIBER, L. B.; D'OLIVEIRA, A. F. P. L. Violência contra as mulheres: interfaces com a saúde. Interface_ Comunicação, Saúde, Educação, v.3 , n.5, 1999. Disponível em: http://www.scielo.br/pdf/icse/v3n5/03. pdf.Acesso em: 25/07/2017.

SCHRAIBER, L. B. et al. Violência de gênero no campo da Saúde Coletiva: conquistas e desafios. Ciência \& Saúde Coletiva, 14 (4), p. 1019-1027, 2009. Disponível em: http://www.scielo.br/scielo.php?script=sci_ arttext\&pid=S1413-81232009000400009. Acesso em: 25/07/2017.

SCOTT, JW. Gênero: uma categoria útil para análise histórica. American Historical Review, 91, 1998. Tradução de Dabat e Ávila. Disponível em: https://edisciplinas.usp.br/pluginfile.php/185058/mod_resource/content/2/ G\%C3\%AAnero -Joan\%20Scott.pdf. Acesso em: 12/02/2017.

SCOTT, JW. O enigma da igualdade. Estudos Feministas, Florianópolis, 13(1): 11-30, 2005. Disponível em: http:// www.culturaegenero.com.br/download/scott.pdf. Acesso em: 23/03/2017.

SOARES, LE. A eficácia pragmática da sensibilidade antropológica e a inversão do modelo defensivo. Observações sobre o lugar do simbólico na política pública de segurança. In: CORRÊA M, organizador. Gênero e cidadania. Campinas: Núcleo de Estudos de Gênero Pagu, Universidade Estadual de Campinas. p. 21-30, 2002. Disponível em: http://www.bibliotecadigital.unicamp.br/document/?down=50798. Acesso em: 02/03/2017.

WAISELFISZ, JJ. Mapa da Violência - Homicídios de Mulheres no Brasil. Brasília: Flacso, 2015. Disponível em: http:// www.mapadaviolencia.org.br/pdf2015/MapaViolencia_2015_mulheres.pdf.

Acesso em: 20/03/2016.

WORLD HEALTH ORGANIZATION (WHO). World Report on Violence and Health. Geneva: WHO, 2002. Disponível em: http://www.who.int/violence_injury_prevention/vio- lence/world_report/en/. Acesso em: 01/11/206.

\section{Agradecimentos}

À agência de fomento: CAPES. 
Dossiê Temático | Pág. 54

RSh REVITA SOCIAIS \& HUMANAS - VOLL 30 / N 3 - 2017 